\title{
Differences in the diet and trophic niche of three sympatric carnivores in a marshland
}

\author{
Zsófia Lanszki $^{1}$ • Győző F. Horváth ${ }^{1} \cdot$ Zsolt Bende $^{2} \cdot$ József Lanszki $^{2}$ (I)
}

Received: 20 December 2018 / Accepted: 26 August 2019 / Published online: 16 September 2019

(C) The Author(s) 2019

\begin{abstract}
In order to conserve wetlands, it is crucial to have reliable knowledge of population and community processes. Our aims were to explore the dietary differences that allow coexistence of carnivores belonging to different trophic guilds, and to detect the presence of the relict Pannonian root vole subspecies (Microtus oeconomus méhelyi) within the Kis-Balaton marshland (Hungary). The 1-year dietary study was based on faecal analysis of the main mammalian predators of the area, i.e. red fox (Vulpes vulpes), martens (Martes spp.) and Eurasian otter (Lutra lutra). Small mammals, mainly Microtus species and water vole (Arvicola amphibius), were the primary foods for each carnivore. The dietary pattern of the otter was unique among European studies. Analysis of frequency data and estimated consumed biomass data revealed significant interspecific and intraspecific (seasonal) foraging differences among the three predators. Based on diets and live trapping of small mammals, foxes and martens selected voles, they selected against mice and shrews. The selection of the root vole was confirmed from faecal samples of foxes and martens. Consequently, faecal analysis of common carnivores can be an effective monitoring tool in providing data about prey species under special habitat conditions. Thus, it may contribute to wetland conservation indirectly.
\end{abstract}

Keywords Kis-Balaton $\cdot$ Microtus oeconomus méhelyi $\cdot$ Trophic relationship $\cdot$ Unique dietary pattern

\section{Introduction}

Marshlands are specific transitional areas as they include features of aquatic and terrestrial ecosystems (Mitsch and Gosselink 1986). Their high productivity, rich and diverse macrovegetation make them ecologically optimal areas, and due to their high biodiversity marshes host unique communities (Báldi et al. 1999; Verboom et al. 2006; Scott et al. 2008). However, marshlands are threatened by considerable human disturbance, management or land use (Jantke and Schneider

Communicated by: Andrzej Zalewski

Electronic supplementary material The online version of this article (https://doi.org/10.1007/s13364-019-00456-z) contains supplementary material, which is available to authorized users.

József Lanszki

lanszkij@gmail.com

1 Department of Ecology, University of Pécs, Ifjúság útja 6, Pécs 7624, Hungary

2 Carnivore Ecology Research Group, Kaposvár University, Guba S. Str. 40, Kaposvár 7400, Hungary
2010; Tousignant et al. 2010). It is essential for the long-term conservation of these wetlands and their communities to have a better knowledge of both population and community processes taking place in these dynamic areas and interspecific interactions such as predation and competition (Foster and Gaines 1991; Ruiz-Olmo et al. 2003; De Bianchi et al. 2014).

Kis-Balaton is a wetland, which was part of Lake Balaton until the nineteenth century, but thereafter, that area was subject to intensive draining (Tátrai et al. 2000). In order to rehabilitate the marshland habitats, the former area was artificially flooded into two stages (1985: Kis-Balaton Water Protection System I - KBWPSI and 1992: Kis-Balaton Water Protection System II - KBWPSII; Tátrai et al. 2000). Nowadays, it is one of the largest marshlands (total area 14,745 ha) and is the most complex habitat system in Hungary, due to its biodiversity and the variety of conservation management (Báldi et al. 1999; Tátrai et al. 2000; Futó 2001; Horváth and Herczeg 2013).

Apart from measurement, inter- and intraspecific comparison of the niche parameters (niche breadth, niche overlap) and preferences can lead to understanding the resource use of competing species, and community dynamics (Hardin 1960; Rosenzweig 1966; Krebs 1989). Diet largely defines the ecological niche of an animal (Kruuk 2006), and therefore food 
separation has an important role in niche segregation (Colwell and Futuyma 1971; Schoener 1974). We analysed the feeding habits and trophic relationships of three sympatric carnivore taxa, namely the red fox (Vulpes vulpes; hereafter fox), martens (stone marten Martes foina and pine marten M. martes) and the Eurasian otter (Lutra lutra; hereafter otter) based on the importance of their relative position within the food web and abundances in the Kis-Balaton marshland. These are widespread carnivores in most parts of Europe, including wetlands, and are primary predators (fox, otter) and common species (fox, martens). Fox (Goszczynski 1986; Kidawa and Kowalczyk 2011; Díaz-Ruiz et al. 2013; Soe et al. 2017) and martens (Zhou et al. 2011; Papakosta et al. 2014) are opportunistic predators that respond to seasonal and geographic fluctuations of prey resources, resulting in significant variation in diet composition across their range. Despite variation, the primary prey of both terrestrial carnivores tends to be small mammals, and vole species are especially preferred (Macdonald 1977; Goszczynski 1986; Jędrzejewska and Jędrzejewski 1998; Lanszki et al. 2007). The otter is mostly a piscivorous species (Erlinge 1967; Kruuk 2006). As they belong to various trophic guilds, dietary differences and coexistence can be expected.

Animals living in dynamic environments have to adapt to changes, especially to fluctuations in the availability of food resources (Becker et al. 2010). In marshes, the fox seasonally preys on birds, lagomorphs or invertebrates in high ratios (Reynolds 1979); the otter can switch temporarily from fish to amphibian or bird (mainly waterfowl) predation (Erlinge 1967; Kruuk 2006; Lanszki and Széles 2006). Unlike in terrestrial and regulated or human-maintained aquatic ecosystems, dietary shifts are influenced more by natural processes in wetlands. The feeding habits and trophic relations of carnivores living in wetlands are less known. We predicted (first prediction) that the feeding habits of sympatric carnivores living in the Kis-Balaton and belonging to different trophic guilds (terrestrial and semiaquatic predators) will respond to seasonal fluctuation in prey resources of the marshland area in different ways to avoid high trophic niche overlap and this will allow coexistence (Hardin 1960; Rosenzweig 1966). In addition to small mammals, terrestrial carnivores will prey on waterfowl all year round in high ratios, and they will select small mammals differently, whilst in addition to fish, the otter will prey on amphibians (especially during spawning, i.e. late winter) and waterfowl (during nesting period) in high ratios.

The Pannonian root vole subspecies (Microtus oeconomus méhelyi), which is one of the rarest mammals of Hungary, and protected since 1974, occurs within the KBWPSII (Horváth and Herczeg 2013). This rodent species mostly inhabits the homogeneous sedge beds and border zone of the reed beds here (Horváth and Gubányi 2006). Considering its habitat specialization (Tast 1966) and priority in terms of its threatened status (92/43 EU Habitat and Species Directive, Annex II and IV; Horváth and Gubányi 2006), the monitoring of abundance and distribution of this relict subspecies has been continuous since 1999. The results of this program have shown that the subpopulations are very sensitive to natural and human-induced disturbance, for example flooding, drying out and burning (Horváth and Herczeg 2013). The presence of the species was detected within the Keleti-Berek (KBWPSII) in 1999-2001, 2005 and 2007-2010. After an increase in water levels due to high rainfall in 2010, the occurrence of root vole within our study area was no longer confirmed by applying a standard monitoring protocol based on small mammal live-trapping methods (Horváth and Gubányi 2006). In respect to detection of this endangered small mammal, the second prediction of our work was that predators, taking advantage of the changing habitat conditions in the area, reach the presumably optimal water-covered root vole habitat patches (Horváth and Herczeg 2013). Therefore, the analysis of faecal samples of predators may be an appropriate method to document the continued presence of the root vole population in the area (Torre et al. 2013).

Our aims, through the analysis of faecal samples of carnivores, were (1) to explore the dietary (diet composition, trophic niche, small mammal selection) differences that allow coexistence of carnivores belonging to different trophic guilds and (2) to detect the presence of root voles in the sedge field of the Kis-Balaton marshland.

\section{Materials and methods}

\section{Study area}

Our investigations were performed in the Kis-Balaton area of Balaton Uplands National Park, Western Hungary, in particular within the strictly protected 5400 ha KBWPSII (Fig. S1, Online Resource 1). Kis-Balaton has been a Natura 2000 (SPA and PSCI) site, and a Ramsar site since 1979. Our study was carried out in the Keleti-Berek $\left(46.70^{\circ} \mathrm{N}, 17.18^{\circ} \mathrm{E}\right.$, $104.5 \mathrm{~m}$ a.s.1.), in the area assigned to the monitoring of the root vole (Horváth and Herczeg 2013), along an abandoned old railroad embankment. This artificial, linear infrastructure ensures sampling and dry, safe and sole passage for terrestrial carnivores in all seasons in the middle of the Keleti-Berek. Both sides of the embankment are covered by homogeneous sedge habitat, where human disturbance is negligible. The dominant species of the plant communities are lesser pondsedge (Carex acutiformis), although in some places, the common reed (Phragmites australis) is dominant. White willow (Salix alba), grey willow (Salix cinerea) and poplars (Populus sp.) are located occasionally along the embankment.

The study area is situated in the continental climatic region, but there are some Mediterranean features. During the study period, from October 2014 to August 2015, mean annual 
temperature was $11.7^{\circ} \mathrm{C}$ (winter $2.1{ }^{\circ} \mathrm{C}$, summer $21.8^{\circ} \mathrm{C}$ ), annual precipitation was $692 \mathrm{~mm}$, and snow cover duration was 20 days (mean snow depth $32 \mathrm{~mm}$; Hungarian Meteorological Service).

There is a large number of waterfowl nests on Kis-Balaton, and the area is an important wintering and migration area for birds and a favourable habitat for amphibians and invertebrates (Báldi et al. 1999; Futó 2001). This is indicated by the number of individuals within the study period: Anatinae 300-4000 ind./month, with peak in December-January; Anserinae 300-10,000 ind./month, with peak in NovemberJanuary; and Fulica atra 50-3500 ind./month, with peak in August (Balaton Uplands National Park's database). Red deer (Cervus elaphus) and wild boar (Sus scrofa) populations are abundant, and other predators also occur in this area, including weasel (Mustela nivalis), stoat (Mustela erminea), Eurasian badger (Meles meles), golden jackal (Canis aureus), wildcat (Felis silvestris), and white-tailed eagle (Haliaeetus albicilla).

The study was conducted during a single but 'typical' year (survey period: October 2014-August 2015), not including high water levels or drought, extreme cold or warm temperatures or extreme rainfall periods. The abundance of birds (survey period $3154 \pm 858$ ind./month, 2010-2018: 3199 \pm 298 ind./month) as well as that of small mammals (survey period $8.6 \pm 1.1$ ind./100 trapnights, 2010-2018: $7.6 \pm 0.9$ ind./100 trapnights), and the relative abundance of mammalian predators (red fox, survey period $2.1 \pm 0.3$ faecal samples $/ 100 \mathrm{~m}$, 2010-2018: $2.2 \pm 0.4$ faecal samples/100 m; martens, survey period $0.18 \pm 0.05$ samples/100 m, 2010-2018: $0.10 \pm 0.15$ samples/100 m; otter, survey period $2.2 \pm 0.4$ samples/ $100 \mathrm{~m}, 2010-2018: 1.8 \pm 0.5$ samples $/ 100 \mathrm{~m}$ ) were average in the Kis-Balaton area (Balaton Uplands National Park's database). Fish abundance in the Keleti-Berek sedge habitat is typically low in comparison with open water surfaces (C. Megyer, pers. comm.).

\section{Faecal sample collection and analysis}

The diet composition and feeding habits of the red fox $(n=482)$, martens $(n=91)$ and otter $(n=342)$ were investigated through the analysis of intact faecal samples collected every 6 weeks between October 2014 and August 2015 (Table S1, Online Resource 2). Samples were collected along a $2.22 \mathrm{~km}$ long standard route, divided into four subsections according to vegetation borders), on the top and the sides of the abandoned railroad embankment running across the marshland. We chose this relatively short sampling route-in addition to those mentioned in the Study Area descriptionbecause there are no similar sampling areas, which are far enough from human disturbance (settlement, traffic, Fig. S1, Online Resource 1) and close $(<0.25 \mathrm{~km})$ to previously known root vole sites. Faecal samples were distinguished based on position, odour, size and shape characteristics (Macdonald 1980; Jędrzejewska and Jędrzejewski 1998; Kruuk 2006). During the laboratory preparation procedure, we checked the questionable samples again (e.g. based on odour). Additionally, carnivore hairs collected from faecal samples were morphologically identified (Teerink 1991; our own reference hair collection). In the case of marten species, morphological characteristics did not allow separation (Pilot et al. 2007), and we therefore merged the marten faecal samples. Finally, samples remaining questionable $(<1 \%)$ were excluded from the analysis. Although the faecal samples of the three carnivore taxa studied can be distinguished from each other by the above methods with high reliability, a small portion of the samples may have remained misclassified (e.g. Baines et al. 2013) due to the absence of DNA analysis. The relative abundance of predators was expressed according to faecal density (D) index values (Kruuk et al. 1986; Webbon et al. 2004).

We prepared the faecal samples by means of a standard procedure (Jędrzejewska and Jędrzejewski 1998). Samples were soaked in water, then washed through a sieve $(0.5 \mathrm{~mm}$ mesh) and finally dried. All food remains were separated, and using a microscope, all feather, bone, dentition, hair and seed remains were identified using keys from Görner and Hackethal (1987), Teerink (1991), Brown et al. (1993), Knollseisen (1996) and our own vertebrate, invertebrate and plant reference collections. The presence of the root vole was confirmed, if species-specific teeth (Görner and Hackethal 1987) were found in the sample.

The percentage composition of food items in the faecal samples was determined on the basis of relative frequency of occurrence $(\mathrm{O}$, proportion of the total number of occurrences of all items in the sample) and biomass consumed (B). To estimate the fresh mass of food ingested (Reynolds and Aebischer 1991), all dry food remains were weighed separately (measured at $0.01 \mathrm{~g}$ accuracy) and the food remains mass data were multiplied by an appropriate conversion factor (i.e. small mammals by 23 , medium-sized mammals by 50 , wild boar by 118 , deer by 15 , birds by 35 , reptiles and amphibians by 18 , fish by 25 , invertebrates (crayfish, insects and molluscs) by 5 and plants (fruits, seeds and other plant material) by 14 for fox and both martens; and small mammals by 9 , ungulates by 15 , birds by 12 , reptiles and amphibians by 18 , fish by 25 , crayfish and molluscs by 7 , insects by 5 and plants by 4 for otter), as summarized from literature data by Jędrzejewska and Jędrzejewski (1998).

The following nine food categories were used in the calculations related to the comparative analysis of the faecal sample composition and the trophic niche for predator species: 1 small mammals (insectivores and rodents), 2 European brown hare (Lepus europaeus), 3 wild ungulates (carrion), 4 birds 
(including eggs), 5 reptiles, 6 amphibians, 7 fish, 8 invertebrates and 9 plants (fruits, seeds and other plant matter).

\section{Live trapping small mammals}

The small mammal availability was surveyed to analyse the small mammal selection of the foxes and martens. In order to avoid multiple counting, the minimum number alive (MNA; based on the new capture data) of small mammals was determined using the capture-mark-recapture method (Krebs 1989). Small mammal trapping periods were carried out in October 2014 (autumn period) and in June, July and August 2015 (summer period from merged monthly data). We distributed glass-doored plastic box-type live-traps (size $185 \times 95 \times$ $75 \mathrm{~mm}$; Horváth and Herczeg 2013) in grids $(6 \times 6$ traps per grid, one grid in autumn and two grids in summer periods, traps placed in sedge vegetation on wet soil) and along two transects (36 traps in the summer period, traps placed on the foot of the railroad embankment on dry soil). This was done for three consecutive nights in each period (108 trap-nights in autumn and 540 trap-nights in summer). Traps were situated $5 \mathrm{~m}$ from each other, baited with bacon and cereals mixed with aniseed extract. We checked the traps twice a day at 07:00 and 19:00. For the identification of captured animals, we used non-individual fur clipping on the head. Autumn markings are not visible in the next summer, and summer markings in each month were applied in a distinctive way. Autumn and summer capture data were treated separately during the evaluation. For selection calculation, we used dominance data (percentage data within community) of each small mammal species based on seasonal MNA data. The small mammals were determined from hairs where there were no suitable teeth found in the faecal sample of carnivores. Species-level microscopic small mammal determinations from hair samples have limitations. To complete preference calculation, we pooled some accurately identified captured species into higher taxonomic groups (e.g. Microtus, Apodemus, shrews), regarding the limitations of the diet analysis.

\section{Data analysis}

General log-linear analyses (STATISTICA 10.0) were used on frequency of occurrence data to test for dietary differences within the carnivore community, i.e. among all three studied carnivore taxa (fox, martens and otter) and season; and separately only between the fox and martens and season, to test differences within the same, terrestrial predator guild. The unit of analysis was faecal samples of carnivores from each season, and the response variable was the presence or absence of the food item (proportion of faecal samples containing or not containing a given food category). The model was fitted using carnivore species and season as categories (independent variables). Owing to the large number of comparisons (nine food categories), we adjusted the level of significance to 0.0055 $(P=0.05 / 9)$ with a Bonferroni correction (Revilla and Palomares 2002).

Estimated consumed biomass data (mass $\times$ conversion factor) were used for the analysis in order to explore the interspecific and intraspecific (seasonal) differences of quantitative data of the carnivores' food consumption (B). Firstly, we examined variables for normality using the Shapiro-Wilk test (STATISTICA 10.0). Because the data did not show normal distribution in most food categories, the nonparametric Kruskal-Wallis median test was used. When significant differences were detected by the median test, we employed Dunn's procedure for post hoc multiple comparisons (Zar 2010).

Trophic niche breadth was calculated in accordance with standardized Levins index ( $B_{\mathrm{A}}$, rating from 0 to 1$)$ according to Hurlbert (1978), and trophic niche overlap using the Renkonen index (Krebs 1989). Ivlev's electivity index ( $E_{\mathrm{i}}$; Krebs 1989) based on small mammal taxa was applied as follows (Krebs 1989): $E_{\mathrm{i}}=\left(r_{\mathrm{i}}-n_{\mathrm{i}}\right) /\left(r_{\mathrm{i}}+n_{\mathrm{i}}\right)$, where $r_{\mathrm{i}}=$ percentage frequency of the given (ith) small mammal taxa in the diet (faecal sample; $\mathrm{O}$ values), and $n_{\mathrm{i}}=$ percentage frequency of the given (ith) small mammal taxa in the environment (dominance data from live trapping). Electivity varies from -1.0 to +1.0 , where -1.0 indicates avoidance (usage in lower proportion than expected based on availability), and +1.0 selected prey.

The standardized trophic niche breadth (calculated seasonally) and trophic niche overlap values (calculated from pairwise seasonal trophic niche overlap values for the three carnivores) were compared with one-way analysis of variance (normal distributed data, ANOVA, Bonferroni post hoc test). Small mammal selection values (mean of autumn and summer values) were compared with paired samples $t$ test between the two terrestrial predators (fox and marten).

The seasons represented by low sample number (martens: winter and spring, otter: summer) were not included in the statistical analyses. A minimum probability level of $P<0.05$ was accepted in all statistical tests, except log-linear analysis $(P<0.0055)$.

\section{Results}

\section{Diet composition}

Small mammals were the primary food type of the red fox (annual mean, O 53.5\%, B 63.0\%), whilst birds (mainly waterfowl, and frequently eggs) were the second most important food (O 17.8\%, B 14.5\%) in the faecal samples (Tables 1 and S2, Online Resource 3). The third most important food was either plants (O 12.6\%, mainly fruit, e.g. cherry Prunus sp.) or wild ungulates (B 9.5\%, mainly wild boar). The main prey species were Microtus voles (O 24.0\%, B 26.1\%), including 
Table 1 Seasonal and annual percentage relative frequency of occurrence and biomass of main food categories in faecal samples of red fox (Vulpes vulpes), martens (Martes spp.) and otter (Lutra lutra) in the Kis-Balaton marshland (Hungary)

\begin{tabular}{|c|c|c|c|c|c|c|c|c|c|c|c|c|c|c|c|}
\hline \multirow[t]{2}{*}{ Food categories } & \multicolumn{5}{|c|}{ Red fox } & \multicolumn{5}{|c|}{ Martens } & \multicolumn{5}{|l|}{ Otter } \\
\hline & $\mathrm{Au}$ & Wi & $\mathrm{Sp}$ & $\mathrm{Su}$ & Ann & $\mathrm{Au}$ & Wi & $\mathrm{Sp}$ & $\mathrm{Su}$ & Ann & $\mathrm{Au}$ & Wi & $\mathrm{Sp}$ & $\mathrm{Su}$ & Ann \\
\hline \multicolumn{16}{|c|}{ Relative frequency of occurrence $(\%)$} \\
\hline Small mammals & 53.2 & 63.2 & 45.3 & 46.7 & 53.5 & 65.8 & 66.7 & 100 & 34.0 & 56.4 & 62.9 & 20.9 & 16.3 & 5.6 & 31.8 \\
\hline Brown hare & 0.8 & & & 2.7 & 1.0 & 1.4 & & & 2.1 & 1.4 & & & & & \\
\hline Ungulates & 1.0 & 7.7 & 5.3 & 8.1 & 4.9 & & & & & & & 0.6 & 3.1 & & 0.8 \\
\hline Birds & 21.1 & 13.8 & 29.3 & 13.5 & 17.8 & 17.8 & 13.3 & & 10.6 & 14.3 & 5.6 & 6.0 & 26.5 & 11.1 & 9.2 \\
\hline Reptiles & 0.5 & 1.2 & & 1.2 & 0.8 & 1.4 & & & & 0.7 & 2.5 & & 2.0 & & 1.1 \\
\hline Amphibians & 0.8 & 0.4 & 2.7 & & 0.6 & & & & & & 4.1 & 24.2 & 8.2 & 2.8 & 14.7 \\
\hline Fish & 1.5 & 4.0 & 1.3 & & 1.7 & & & & 2.1 & 0.7 & 11.2 & 28.1 & 20.4 & 61.1 & 23.7 \\
\hline Invertebrates & 7.1 & 4.5 & 6.7 & 9.3 & 7.0 & 4.1 & 6.7 & & 10.6 & 6.4 & 13.2 & 20.3 & 23 & 19.4 & 18.6 \\
\hline Plants & 14.0 & 5.3 & 9.3 & 18.5 & 12.6 & 9.6 & 13.3 & & 40.4 & 20.0 & 0.5 & & & & 0.2 \\
\hline$B_{\mathrm{A}}$ & 0.23 & 0.17 & 0.28 & 0.31 & 0.24 & 0.14 & 0.13 & 0 & 0.29 & 0.21 & 0.16 & 0.43 & 0.49 & 0.17 & 0.31 \\
\hline$\pm \mathrm{SE}$ & & & & & 0.03 & & & & & 0.07 & & & & & 0.09 \\
\hline \multicolumn{16}{|l|}{ Biomass consumed $(\%)$} \\
\hline Small mammals & 70.1 & 79.5 & 61.3 & 42.3 & 63.0 & 86.3 & 72.1 & 100 & 25.9 & 61.1 & 71.2 & 34.9 & 19.0 & 9.7 & 45.7 \\
\hline Brown hare & 3.9 & & & 12.2 & 5.1 & 7.9 & & & 5.8 & 5.4 & & & & & \\
\hline Ungulates & 0.1 & 11.7 & 2.6 & 20.3 & 9.5 & & & & & & & $+^{\mathrm{a}}$ & 0.4 & & + \\
\hline Birds & 18.7 & 6.6 & 33.9 & 10.1 & 14.5 & 3.3 & 22.1 & & 12.5 & 10.2 & 4.6 & 5.0 & 62.4 & 8.6 & 9.5 \\
\hline Reptiles & + & + & & 0.1 & + & + & & & & + & 1.6 & & 0.7 & & 0.7 \\
\hline Amphibians & 0.3 & 0.3 & 1.2 & & 0.3 & & & & & & 11.7 & 24.8 & 3.1 & 9.0 & 17.3 \\
\hline Fish & 0.7 & 1.5 & + & & 0.6 & & & & + & + & 9.4 & 32.4 & 12.9 & 61.4 & 24.1 \\
\hline Invertebrates & 0.1 & 0.2 & 0.2 & + & 0.1 & + & + & & 0.1 & + & 1.5 & 2.8 & 1.4 & 11.3 & 2.7 \\
\hline Plants & 6.1 & 0.3 & 0.9 & 14.9 & 6.9 & 2.5 & 5.9 & & 55.7 & 23.2 & + & & & & + \\
\hline$B_{\mathrm{A}}$ & 0.12 & 0.07 & 0.13 & 0.34 & 0.16 & 0.04 & 0.09 & 0 & 0.19 & 0.12 & 0.11 & 0.30 & 0.16 & 0.18 & 0.19 \\
\hline$\pm \mathrm{SE}$ & & & & & 0.06 & & & & & 0.07 & & & & & 0.04 \\
\hline Number of samples ${ }^{b}$ & 183 & 143 & 40 & 116 & 482 & 46 & 13 & 5 & 27 & 91 & 126 & 152 & 48 & 16 & 342 \\
\hline Number of food items & 393 & 247 & 75 & 259 & 974 & 73 & 15 & 5 & 47 & 140 & 197 & 335 & 98 & 36 & 666 \\
\hline
\end{tabular}

$A u$ autumn, Wi winter, $S p$ spring, $S u$ summer, $A n n$ annual mean, $B_{A}$ standardized trophic niche breadth value, $\pm S E$ standard error value to annual mean data

${ }^{\text {a }}$ Biomass under $0.05 \%$

${ }^{\mathrm{b}}$ Faecal samples collected between October 2014 and August 2015

root vole, which were found in eight cases in the autumn and winter samples. European water vole (Arvicola amphibius) consumption was also important (O 16.2\%, B 25.5\%).

The most important food for martens was small mammals (annual mean, O 56.4\%, B 61.1\%), the secondary food was plants (O $20.0 \%$, B $23.2 \%$, mainly fruit, e.g. cherry) and the third most important food type was birds (O 14.3\%, B 10.2\%, mainly waterfowl and small passerines) (Tables 1 and S2, Online Resource 3). Root vole was found in the autumn samples three times. The main prey species of martens were Microtus voles and water vole.

Small mammals were the primary food type for the otter, too (annual mean, O $31.8 \%$, B $45.7 \%$ ), the secondary food was fish (O 23.7\%, B 24.1\%, mostly cyprinids), and the third most important food was amphibians (O 14.7\%, B 17.3\%, frogs and toads) (Tables 1 and S2, Online Resource 3). The majority of the small mammals were water vole and Microtus species. Consumption of birds (especially of waterfowl) in spring was high $(\mathrm{O} 26.5 \%$, B 62.4\%).

The occurrence of other food types (Table 1) was occasional in faecal samples or had a low proportion of consumed biomass.

\section{Inter- and intraspecific differences in dietary composition and trophic niche}

With log-linear analysis (Table 2) we found significant differences in the consumption rates of almost all food types (except for hare and reptiles) among the three carnivore taxa. This is due to the specific diet composition of otters; overall, fish, 
Table 2 Results of log-linear models for the frequencies of occurrence of food types in the faecal samples of red fox (Vulpes vulpes), martens (Martes spp.) and otter (Lutra lutra) during four seasons in the Kis-Balaton marshland (Hungary), showing the effect of carnivore species and their interaction

\begin{tabular}{|c|c|c|c|c|c|c|c|}
\hline \multirow[t]{2}{*}{ Item } & \multirow[t]{2}{*}{ Effect } & \multicolumn{3}{|c|}{ Fox, martens and otter } & \multicolumn{3}{|c|}{ Fox and martens } \\
\hline & & $d f$ & $\chi^{2}$ & $P$ & $d f$ & $\chi^{2}$ & $P$ \\
\hline \multirow[t]{3}{*}{ Small mammals } & Species & 2 & 62.5 & $<0.0001$ & 1 & 2.3 & 0.133 \\
\hline & Season & 3 & 95.0 & $<0.0001$ & 3 & 29.4 & $<0.0001$ \\
\hline & Interaction & 6 & 215.6 & $<0.0001$ & 3 & 52.4 & $<0.0001$ \\
\hline \multirow[t]{3}{*}{ Brown hare } & Species & 2 & 2.0 & 0.370 & 1 & 0.6 & 0.427 \\
\hline & Season & 3 & 9.1 & 0.028 & 3 & 7.5 & 0.057 \\
\hline & Interaction & 6 & 206.8 & $<0.0001$ & 3 & 51.4 & $<0.0001$ \\
\hline \multirow[t]{3}{*}{ Ungulates } & Species & 2 & 22.1 & $<0.0001$ & 1 & 3.9 & 0.049 \\
\hline & Season & 3 & 29.1 & $<0.0001$ & 3 & 25.8 & $<0.0001$ \\
\hline & Interaction & 6 & 206.0 & $<0.0001$ & 3 & 50.0 & $<0.0001$ \\
\hline \multirow[t]{3}{*}{ Birds } & Species & 2 & 30.2 & $<0.0001$ & 1 & 3.2 & 0.072 \\
\hline & Season & 3 & 46.0 & $<0.0001$ & 3 & 19.5 & 0.000 \\
\hline & Interaction & 6 & 216.9 & $<0.0001$ & 3 & 53.6 & $<0.0001$ \\
\hline \multirow[t]{3}{*}{ Reptiles } & Species & 2 & 1.0 & 0.596 & 1 & 1.2 & 0.268 \\
\hline & Season & 3 & 2.2 & 0.527 & 3 & 52.6 & $<0.0001$ \\
\hline & Interaction & 6 & 212.6 & $<0.0001$ & 3 & 1.0 & 0.803 \\
\hline \multirow[t]{3}{*}{ Amphibians } & Species & 2 & 113.7 & $<0.0001$ & 1 & 0.8 & 0.369 \\
\hline & Season & 3 & 69.7 & $<0.0001$ & 3 & 5.9 & 0.117 \\
\hline & Interaction & 6 & 171.5 & $<0.0001$ & 3 & 52.7 & $<0.0001$ \\
\hline \multirow[t]{3}{*}{ Fish } & Species & 2 & 121.3 & $<0.0001$ & 1 & 0.7 & 0.414 \\
\hline & Season & 3 & 45.6 & $<0.0001$ & 3 & 8.7 & 0.034 \\
\hline & Interaction & 6 & 161.1 & $<0.0001$ & 3 & 52.9 & $<0.0001$ \\
\hline \multirow[t]{3}{*}{ Invertebrates } & Species & 2 & 51.9 & $<0.0001$ & 1 & 0.2 & 0.631 \\
\hline & Season & 3 & 11.8 & 0.008 & 3 & 7.2 & 0.066 \\
\hline & Interaction & 6 & 210.5 & $<0.0001$ & 3 & 52.5 & $<0.0001$ \\
\hline \multirow[t]{3}{*}{ Plants } & Species & 2 & 68.5 & $<0.0001$ & 1 & 0.1 & 0.747 \\
\hline & Season & 3 & 46.0 & $<0.0001$ & 3 & 44.0 & $<0.0001$ \\
\hline & Interaction & 6 & 157.5 & $<0.0001$ & 3 & 49.9 & 0.014 \\
\hline
\end{tabular}

$P$ values (with Bonferroni corrections, $P<0.0055)$ in italics are significant

amphibians and invertebrates occurred more frequently in faecal samples of the otter, whilst birds, plants and small mammals occurred more frequently in samples of terrestrial predators, whilst the differences between the fox and the martens were not significant (Tables 1 and 2). We found significant seasonal differences in some food types. Generally, in the case of the terrestrial carnivores, small mammals and birds had a lower occurrence in faecal samples in summer, ungulates in autumn (detected in fox only), and plants were consumed most frequently in autumn. As for the otter, small mammals had a greater occurrence in the faecal samples collected in autumn and their consumption frequency decreased rapidly until spring and summer; however, consumption of amphibians in winter, birds in spring and fish in the summer samples occurred most frequently.

Based on the estimated consumed biomass data (mass $x$ conversion factor), the consumption of small mammals based on faecal analysis was significantly different when the three mammalian carnivores were compared [Kruskal-Wallis test, $H(2, N=882)=94.01, P<0.001]$; according to post hoc test, foxes consumed significantly higher proportions of small mammals compared to martens (post hoc test, $z=6.02$, $P<0.001)$ and otters $(z=8.69, P<0.001)$. Regarding vertebrate prey taxa, further significant difference between species was revealed, in the case of birds $(H(2, N=882)=25.56$, $P<0.001)$, amphibians $(H(2, N=882)=142.73, P<0.001)$ and fish $(H(2, N=882)=177.23, P<0.001)$, whereas for lagomorphs, ungulates and reptiles, the difference was not significant $(P>0.05)$. Bird consumption of foxes had higher proportions than that of otters $(z=3.89, P<0.001)$, whereas otters took higher proportions of amphibians and fish than foxes (amphibians: $z=6.18, P<0.001$, fish: $z=8.15$, $P<0.001$ ) and martens (amphibians: $z=3.59, P<0.001$; fish: $z=4.82, P<0.001)$. These three carnivores also differed in 
their consumption of invertebrates $(H(2, N=882)=58.04$, $P<0.001)$ and plants $(H(2, N=882)=95.64, P<0.001)$. Otters took higher proportions of invertebrates than foxes $(z=5.11, P<0.001)$ and martens $(z=3.12, P=0.005)$, and foxes took higher proportions of plants than martens $(z=$ 5.53, $P<0.001)$ and otters $(z=4.35, P<0.001)$.

Seasonal differences were analysed in the case of the four most important prey taxa for the carnivores in the habitat: small mammals, birds, amphibians and fish. Foxes showed seasonal differences in the consumption of birds only $(H(3$, $N=482)=19.99, P<0.001)$, being higher in autumn $(z=$ $2.86, P=0.025)$ and spring $(z=3.14, P=0.009)$ than in winter. Seasonal differences in the case of martens (considering the autumn and summer samples) occurred only in small mammal consumption $(H(1, N=73)=8.48, P=0.003)$, being higher in autumn $(z=2.89, P=0.003)$ than in summer. Significant seasonal differences were found in all four food categories of otters (considering the autumn, winter and spring samples). Otters took higher proportions of small mammals $(H(2, N=327=67.90, P<0.001)$ in autumn than in winter $(z=6.20, P<0.001)$ and spring $(z=7.05, P<0.001)$, and took higher proportions of small mammals in winter than in spring $(z=2.72, P<0.020)$. The consumption of birds $(H(2, N=$ $327)=56.42, P<0.001)$ had larger proportions in spring than in autumn $(z=4.79, P<0.001)$ and in winter $(z=4.45$, $P<0.001)$. The consumption of amphibians $(H(2, N=$ $342)=60.53, P<0.001)$ had larger proportions in winter than in autumn $(z=5.83, P<0.001)$ and spring $(z=3.51, P=$ $0.001)$. The consumption of fish $(H(2, \mathrm{~N}=327)=37.78$, $P<0.001)$ had higher proportions in winter than in autumn $(z=5.31, P<0.001)$.

The values of standardized trophic niche breadth (Table 1) based on the evaluation of $\mathrm{O}$ data (ANOVA, $F_{2}=0.51, P=$ $0.623)$ or the $B$ values $\left(F_{2}=0.31, P=0.745\right)$ among carnivores were not significantly different. Similarly, trophic niche overlap (Table 3, $\mathrm{O}$ data, $F_{2}=1.23, P=0.336$; B data, $F_{2}=$ $0.39, P=0.688$ ) was also not significantly different. Fox, marten and otter faecal samples contained 37, 18 and 31 different animal taxa (i.e. taxonomic species or higher classification), as well as 13,7 and 1 plant taxa, respectively.

Table 3 Trophic niche overlaps (mean \pm SE) of red fox (Vulpes vulpes), martens (Martes spp.) and otter (Lutra lutra) in the Kis-Balaton marshland (Hungary) calculated from the percentage relative frequency of occurrence $(\mathrm{O}$, above the diagonal) and percentage biomass $(\mathrm{B}$, below the diagonal) of food types in the faecal samples

\begin{tabular}{lllll}
\hline Carnivores & Red fox & Martens & Otter & Mean (O) \\
\hline Red fox & & $80.2 \pm 5.6$ & $54.0 \pm 9.5$ & $64.5 \pm 8.4$ \\
Martens & $67.6 \pm 10.8$ & & 74.5 & $78.4 \pm 3.8$ \\
Otter & $57.0 \pm 9.7$ & 74.6 & & $59.2 \pm 8.5$ \\
Mean (B) & $61.2 \pm 6.7$ & $69.9 \pm 6.6$ & $61.4 \pm 8.0$ & \\
\hline
\end{tabular}

\section{Small mammal selection}

The autumn catches ( $n=36$ individuals) consisted mainly of striped field mouse (Apodemus agrarius; $41.7 \%$ ) and shrews (Miller's water shrew Neomys anomalus, water shrew $N$. fodiens and common shrew Sorex araneus; $41.7 \%$ ). Harvest mouse (Micromys minutus; $16.7 \%$ ) was also captured. The summer catches $(n=387)$ were dominated by the striped field mouse (65.1\%; in one case wood mouse A. sylvaticus), but harvest mouse (19.1\%), shrews (lesser white-toothed shrew Crocidura suaveolens, Miller's water shrew, water shrew and common shrew; 11.1\%), field vole (Microtus agrarius; $2.6 \%)$ and water vole $(2.1 \%)$ were also captured. Although bank vole (Myodes glareolus), brown rat (Rattus norvegicus), water vole and root vole were not captured in the sedge field, they occurred in the diet of predators.

Based on small mammal capture and consumption data, foxes and martens also selected Microtus voles and water vole, whilst both of them selected against Apodemus mice, harvest mouse and shrews (Fig. 1). Considering the selection of any of the small mammals (paired samples $t$ test, $t_{4}=0.46$, $P=0.668$ ), we did not find significant differences between terrestrial predators. In autumn, the otter consumed Microtus voles, water vole and brown rat, but these were not captured in the field.

\section{Discussion}

\section{Dietary patterns}

In the sedge field of the Kis-Balaton marshland, the feeding habits of the terrestrial red fox, the martens and the semiaquatic otter showed similarity in that their primary food types were small mammals, and they consumed other food types in high proportions only periodically. We also found seasonal differences among carnivores in the consumption of small mammals and some other food types characteristic to wetlands. This supports our first prediction (i.e. 'dynamically adaptable feeding habits which allow coexistence') in several respects.

The dynamically adaptable feeding habits of the red fox indicated that the consumption of the primarily important small mammals showed seasonal fluctuation, bird consumption was periodically high (especially in the spring breeding and autumn bird migration periods), and the consumption of other food types was subordinate. This dietary pattern supported our first prediction, the highly frequent waterfowl consumption, which was at least regionally unique in the marshes (Reynolds 1979; Lanszki 2005) and terrestrial habitats (e.g. Jędrzejewska and Jędrzejewski 1998; Díaz-Ruiz et al. 2013; Panek 2013; Soe et al. 2017). The frequent bird and bird egg consumption may relate to high bird abundance in the area (Báldi et al. 1999; Futó 2001; Balaton Uplands National 
Fig. 1 Estimated small mammal selection of red fox (Vulpes vulpes) (black columns) and martens (Martes spp.) (white columns) in the Kis-Balaton marshland (Hungary). $E_{\mathrm{i}}$ Ivlev's electivity index

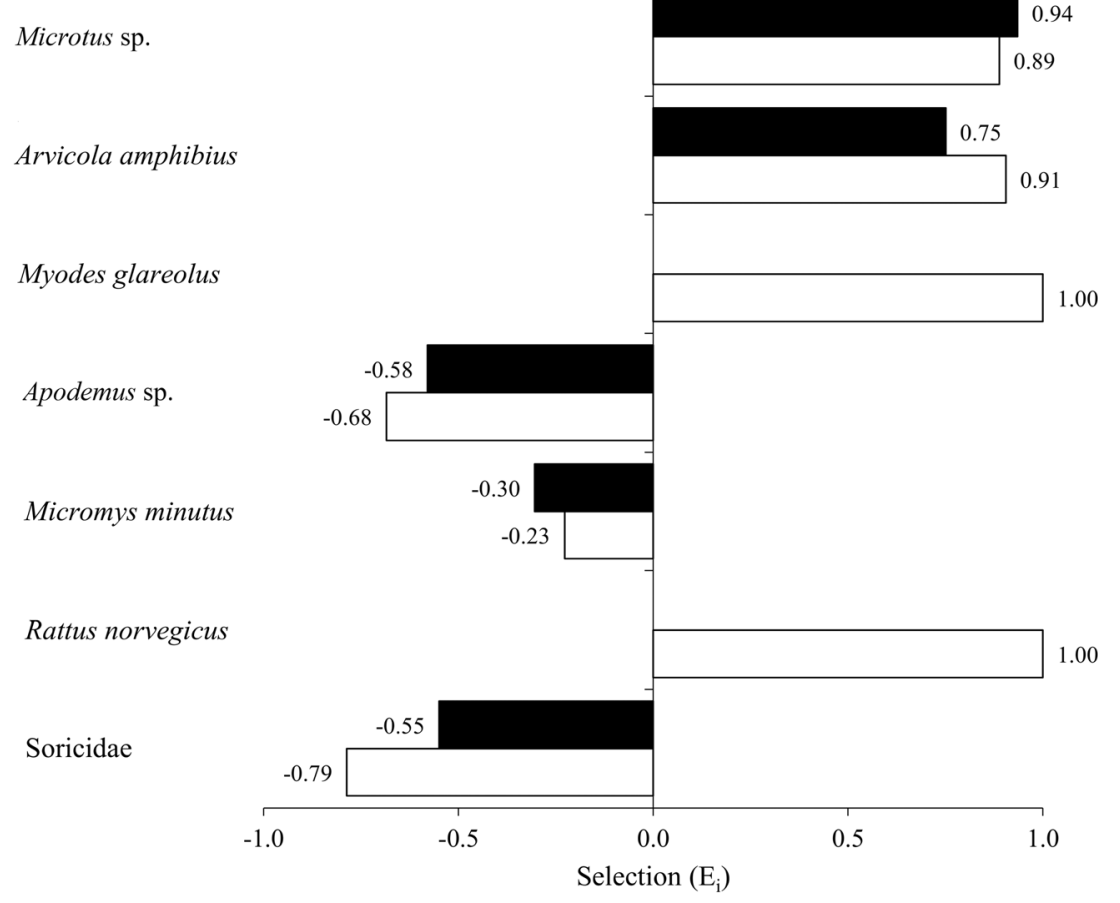

performed in the marshland with stone marten (Lodé 1994). However, this does not show any particular deviation from the diet compositions of stone and pine martens known from terrestrial areas (Zhou et al. 2011; Papakosta et al. 2014). Thus, our first prediction for the martens is only partially supported.

The dietary pattern of the otter is unique among European studies, because of an overall extremely high consumption of small mammals and less pronounced fish consumption with relatively broad trophic niche detected in our area. The unusual dietary pattern, however, supports our first prediction. It indicates highly adaptive and unusual foraging in a transitional marshland habitat, and confirms that otters are highly specialized foragers (Kruuk 2006). However, besides the wellknown fish specialization, temporary frequent consumption of other food types is known (Erlinge 1967; Clavero et al. 2003; Kruuk 2006). The consumption ratio of fish was only one third, whilst the consumption of small mammals was 15 20 times more common than the mean values described in European studies (Lanszki et al. 2016). Fish consumption under $25 \%$ throughout the year is unknown, even $30-40 \%$ of fish consumption is rarely reported (Erlinge 1967; Kyne et al. 1989; Gourvelou et al. 2000), and the consumption of mammals reached up to 15-18\% (Weber 1990; Sulkava 1996; Gourvelou et al. 2000). This could have been largely due to the low fish abundance in the shallow water and the less drained sedge field area. However, the $D$-index values (Fig. S2, Online Resource 4) indicate the regular presence of otters in the area, and it is known that a broad spectrum of aquatic habitats may be suitable. Bird consumption was three times higher than the mean values reported in European summary 
studies; however, Erlinge (1967) experienced higher values along Swedish lakes. The consumption of amphibians, which are the second most important food in freshwater habitats in the temperate zone, was not considerably higher than the mean values found in European analyses. The low consumption ratios of other food types (reptiles, crayfish) were similar in most of the studies performed in temperate freshwater habitats (Clavero et al. 2003; Krawczyk et al. 2016; Lanszki et al. 2016). The dietary pattern of the otter differs also from other marshes, where the diet is still dominated by fish; however, besides fish, the otters relatively frequently consume amphibians (Lodé 1989), birds (Miranda et al. 2008) or crayfish (Delibes and Adrián 1987).

The unusually high proportions of small mammal and bird consumption and low fish consumption ratios prompt the question whether this is profitable for the otter. The European pond turtle (Emys orbicularis) or frog-dominated food can be profitable for the otter in severe winter periods with limited food availability (Lanszki et al. 2006). Based on a simple calculation from the study mentioned, it seems that the energy content of the unique diet compositions found from autumn to spring was similar to the fish-dominated summer diet (Fig. S3, Online Resource 5). The limitation of this calculation is that the handling time of various prey species, the success rate and the cost of predation (Brown and Kotler 2004; Kruuk 2006) are unknown.

\section{Trophic niche partitioning}

The trophic niche of the terrestrial carnivores was relatively narrow in spite of the diversity of the consumed species, and their dietary patterns showed inter-seasonal differences. These indicate that depending on food resources and accessibility in a given period, these carnivores use one or more food types in higher proportion (McDonald 2002), so they have characteristics of both generalist and specialist predators. The trophic niche of the otter was relatively broad (c.f. Clavero et al. 2003; Krawczyk et al. 2016; Lanszki et al. 2016) due to the unique dietary pattern and contrary to what we expected based on the 'habitat stability hypothesis' (Ruiz-Olmo and Jiménez 2009). The question arises whether the consumption of abundant small mammals and birds is profitable for the otter. This topic would be worth investigating.

Despite the relatively high trophic niche overlap values, the carnivores studied occurred sympatrically in the area. High trophic niche overlap values do not necessarily mean competition, particularly if the sources are not limited (MacArthur and Levins 1967; Krebs 1989), though the sources are not exactly known in the Kis-Balaton. High trophic niche overlap without competition has been described in many studies (e.g. Serafini and Lovari 1993; Lanszki et al. 2007; Santos et al. 2007). The niche partition of species is enhanced by differences in dietary patterns and the flexibility of feeding habits (species-rich food, switching, differences in food preferences), but it can also be influenced by source partition (Hardin 1960; Rosenzweig 1966) based on other features of the prey species (e.g. different size, activity, habitat use). However, the occurrence frequencies of coexisting predators can vary with time. It is indirectly indicated by the seasonally changing D-indices (Fig. S2, Online Resource 4), although these values could be influenced by numerous factors, for example the seasondependent differences in hiding and territory marking behaviour, home range size and habitat use (Kruuk et al. 1986; Jędrzejewska and Jędrzejewski 1998). The number of investigated individuals could have been low, especially in the case of martens.

\section{Food selection}

In the Keleti-Berek terrestrial, carnivores selected slowermoving voles from the rodent community and showed less of a selection for Apodemus mice, which are characteristically fast-moving, very agile species that are difficult to prey upon (Jędrzejewski and Jędrzejewska 1992). Similar selections have been found in other habitat types (Macdonald 1977; Lanszki et al. 2007) and also in marshes (Lanszki 2005). The root vole is relatively bigger (body mass $20-45 \mathrm{~g}$, authors' own measurements) than other species from the Microtus genus selected by carnivores. Furthermore, the larger bodied water vole and the brown rat are also selected, so it can be assumed that preying on these rodents is profitable (Carbone et al. 2007); therefore, searching investment is profitable (Kruuk 2006). However, not only resource, for example abundance of a particular prey item, but also access, namely presence of a particular prey item in preferred foraging habitat can influence dietary preferences or selection of predators (Gendron 1987; Nilsen et al. 2012). The abundance of small mammals in the survey period was average within a 9-year monitoring period (detailed in 'Material and methods'). The root vole inhabits sedge and wet habitats, which are unfavourable for the red fox and martens (Jędrzejewska and Jeedrzejewski 1998); thus, with water cover, the selection for the root vole is less likely. Similarly, that the small-sized harvest mouse was also a selected prey may be related to its availability in the study area.

\section{Confirmed root vole presence}

The occurrence of the root vole subspecies in the marshland was confirmed by the fact that it has been identified from several fox and marten faecal samples from different seasons which supports our second prediction. This also means that certain common carnivore species-under specific circumstances - can be used to detect the presence of nearby rare, elusive prey species (Torre et al. 2013). Since the diet of 
the barn owl (Tyto alba) usually reflects real changes in the availability of small mammals, pellet analysis of this nocturnal raptor is frequently used as an indirect method in the monitoring of small mammal communities, along with the direct method of conventional live-trapping (Torre et al. 2004; Avenant 2005). The faecal analysis of common carnivores is a proposed additional monitoring tool to survey small mammal communities and to monitor their spatio-temporal variations (Torre et al. 2013), especially if barn owl pellets are less available in non-accessible areas which are free from buildings and trees.

In conclusion, the changes in characteristics of the food resources of the marshland are indicated by the detected small mammal dominated diets, by small mammal selections, and by the consumption of other food types, which have high temporary proportions. Dynamically adaptable feeding habits were reflected in interspecific and intraspecific (seasonal) foraging differences among of the three predators, i.e. in niche separation, which allow coexistence. The unique dietary pattern detected in the case of otter indicates highly adaptive foraging in a transitional wetland, and confirms that otters can temporarily become specialized foragers. Furthermore, a simple faecal analysis of common carnivores has proved the presence of the root vole in the area. These pieces of information could facilitate the conservation management of the dynamically changing marshlands.

Acknowledgements Thanks to M. Magyari (monitoring coordinator), B. Trócsányi, G. Yoxon and anonymous reviewers for their valuable advice and comments on early drafts of the manuscript and G. Jánosa for small mammal teeth identification, and the Hungarian Meteorological Service (OMSZ) for meteorological data.

Funding information Open access funding provided by Kaposvár University (KE). This study was supported by the Balaton Uplands National Park Directorate and the EFOP-3.6.2-16-2017-00014 project.

\section{Compliance with ethical standards}

Conflict of interest The authors declare that they have no conflict of interest.

Ethical approval All applicable international, national and/or institutional guidelines for the care and use of animals were followed. All studies, including live trapping of small mammals, were permitted by the local, competent authority (VAV/KTF/1258-8/2015).

Open Access This article is distributed under the terms of the Creative Commons Attribution 4.0 International License (http:// creativecommons.org/licenses/by/4.0/), which permits unrestricted use, distribution, and reproduction in any medium, provided you give appropriate credit to the original author(s) and the source, provide a link to the Creative Commons license, and indicate if changes were made.

\section{References}

Avenant NL (2005) Barn owl pellets: a useful tool for monitoring small mammal communities. Belg J Zool 135:39-43

Baines D, Aebischer N, Macleod A, Woods J (2013) Pine marten Martes martes and red fox Vulpes vulpes sign indices in Scottish forests: population change and reliability of field identification of scats. Wild1 Biol 19:490-496

Báldi A, Moskát C, Palkó S, Gáti E (1999) Effects of reconstruction works on the breeding birds of the Kis-Balaton. Vogelwelt 120: 273-276

Becker NI, Rothenwöhrer C, Tschapka M (2010) Dynamic feeding habits: efficiency of frugivory in a nectarivorous bat. Can J Zool 88:764-773

Brown JS, Kotler BP (2004) Hazardous duty pay and the foraging cost of predation. Ecol Lett 7:999-1014

Brown R, Ferguson J, Lawrence M, Lees D (1993) Federn, Spuren und Zeichen der Vögel Europas: Ein Feldführer. Aula-Verlag, Wiesbaden

Carbone C, Teacher A, Rowcliffe JM (2007) The costs of carnivory. PLoS Biol 5:e22

Cavallini P, Volpi T (1996) Variation in the diet of the red fox in a Mediterranean area. Rev Ecol Terre Vie 51:173-189

Clavero M, Prenda J, Delibes M (2003) Trophic diversity of the otter (Lutra lutra L.) in temperate and Mediterranean freshwater habitats. J Biogeogr 30:761-769

Colwell RK, Futuyma DJ (1971) On the measurement of niche breadth and overlap. Ecology 52:567-576

De Bianchi CR, Campos RC, Xavier-Filho NL, Olifiers N, Gompper ME, Mourão G (2014) Intraspecific, interspecific, and seasonal differences in the diet of three mid-sized carnivores in a large neotropical wetland. Acta Theriol 59:13-23

Delibes M, Adrián I (1987) Effects of crayfish introduction on otter Lutra lutra food in the Doñana National Park, SW Spain. Biol Conserv 42: $153-159$

Díaz-Ruiz F, Delibes-Mateos M, García-Moreno JL, López-Martín JM, Ferreira C, Ferreras P (2013) Biogeographical patterns in the diet of an opportunistic predator: the red fox Vulpes vulpes in the Iberian Peninsula. Mammal Rev 43:59-70

Erlinge S (1967) Food habits of the fish-otter Lutra lutra L. in south Swedish habitats. Viltrevy 4:371-443

Ferrari N, Weber JM (1995) Influence of the abundance of food resources on the feeding habits of the red fox, Vulpes vulpes, in western Switzerland. J Zool 236:117-129

Foster J, Gaines MS (1991) The effects of a successional habitat mosaic on a small mammal community. Ecology 72:1358-1373

Futó J (2001) Natural heritage of the Balaton-uplands National Park II. The region of Kis-Balaton. Balaton-Uplands National Park Directorates, Veszprém

Gendron RP (1987) Models and mechanisms of frequency-dependent predation. Am Nat 130:603-623

Görner M, Hackethal H (1987) Säugetiere Europas. Neumann Verlag, Leipzig

Goszczynski J (1986) Diet of foxes and martens in Central Poland. Acta Theriol 31:491-506

Gourvelou E, Papageorgiou N, Neophytou C (2000) Diet of the otter Lutra lutra in lake Kerkini and stream Milli-Aggistro, Greece. Acta Theriol 45:35-44

Hardin G (1960) The competitive exclusion principle. Science 131:12921297

Horváth G, Gubányi A (2006) Hungarian national action plan for Pannonian root vole (Microtus oeconomus mehelyi). Ministry of Environment and Water, Budapest 
Horváth GF, Herczeg R (2013) Site occupancy response to natural and anthropogenic disturbances of root vole: conservation problem of a vulnerable relict subspecies. J Nat Conserv 21:350-358

Hurlbert SH (1978) The measurement of niche overlap and some relatives. Ecology 59:67-77

Jantke K, Schneider UA (2010) Multiple-species conservation planning for European wetlands with different degrees of coordination. Biol Conserv 143:1812-1821

Jędrzejewska B, Jędrzejewski W (1998) Predation in vertebrate communities. The Bialowieza primeval Forest as a case study. SpringerVerlag, Berlin

Jędrzejewski W, Jędrzejewska B (1992) Foraging and diet of the red fox Vulpes vulpes in relation to variable food resources in Bialowieza National Park, Poland. Ecography 15:213-221

Jensen B, Sequeira DM (1978) The diet of the red fox (Vulpes vulpes L.) in Denmark. Dan Rev Game Biol 10:1-16

Kidawa D, Kowalczyk R (2011) The effects of sex, age, season and habitat on diet of the red fox Vulpes vulpes in northeastern Poland. Acta Theriol 56:209-218

Knollseisen M (1996) Fischbestimmungsatlas, als Grundlage für nahrungsökologische Untersuchungen. Boku-Reports on Wildlife Resarch and Game Management, Wien

Kozena I (1988) Diet of the red fox (Vulpes vulpes) in agrocoenoses in southern Moravia. Acta Scientiarum Naturalium Academiae Scientiarum Bohemoslovacae 22:1-24

Krawczyk AJ, Bogdziewicz M, Majkowska K, Glazaczow A (2016) Diet composition of the Eurasian otter Lutra lutra in different freshwater habitats of temperate Europe: a review and meta-analysis. Mammal Rev 46:106-113

Krebs CJ (1989) Ecological methodology. Harper Collins, New York

Kruuk H (2006) Otters. Ecology, behaviour and conservation. Oxford Univ. Press, Oxford

Kruuk H, Conroy JWH, Glimmerween U, Ouwerkerk EJ (1986) The use of spraints to survey populations of otters Lutra lutra. Biol Conserv 35:187-194

Kyne MJ, Smal CM, Fairley JS (1989) The food of otters Lutra lutra in the Irish midlands and a comparison with that of mink Mustela vison in the same region. Proc Roy Ir Acad B Biol Geol Chem Sci 89:33-46

Lanszki J (2005) Diet composition of red fox during rearing in a moor: a case study. Folia Zool 54:213-216

Lanszki J, Széles LG (2006) Feeding habits of otters on three moors in the Pannonian ecoregion (Hungary). Folia Zool 55:358-366

Lanszki J, Molnár M, Molnár T (2006) Factors affecting the predation of otter (Lutra lutra) on European pond turtle (Emys orbicularis). J Zool 270:219-226

Lanszki J, Zalewski A, Horváth G (2007) Comparison of red fox and pine marten food habits in a deciduous forest. Wildl Biol 13:258-271

Lanszki J, Lehoczky I, Kotzé A, Somers MJ (2016) Diet of otters (Lutra lutra) in various habitat types in the Pannonian biogeographical region compared to other regions of Europe. PeerJ 4:e2266

Lodé T (1989) La loutre en Loire-Atlantique Lutra lutra L. 1758. Bulletin de la Société Vaudoise des Sciences Naturelles 11:69-76

Lodé T (1994) Feeding habits of the stone marten Martes foina and environmental factors in western France. Z Säugetierkd - Mamm Biol 59:189-191

MacArthur JW, Levins R (1967) The limiting similarity, convergence and divergence of co-existing species. Am Nat 101:377-385

Macdonald DW (1977) On food preference in the red fox. Mammal Rev $7: 7-23$

Macdonald DW (1980) Patterns of scent marking with urine and faeces amongst carnivore communities. Symp Zool Soc Lond 45:107-139

McDonald RA (2002) Resource partitioning among British and Irish mustelids. J Anim Ecol 71:185-200
Miranda R, Copp GH, Williams J, Beyer K, Gozlan RE (2008) Do Eurasian otters Lutra lutra (L.) in the Somerset levels prey preferentially on non-native fish species? Fund Appl Limnol 172:339-347

Mitsch WJ, Gosselink JG (1986) Wetlands. Van Nostrand Reinhold, New York

Nilsen EB, Christianson D, Gaillard JM, Halley D, Linnell JD, Odden M, Panzacchi M, Toïgo C, Zimmermann B (2012) Describing food habits and predation: field methods and statistical considerations. In: Boitani L, Powell RA (eds) Carnivore ecology and conservation: a handbook of techniques. Oxford Univ. Press, Oxford, pp 256-272

Panek M (2013) Long-term changes in the feeding pattern of red foxes Vulpes vulpes and their predation on brown hares Lepus europaeus in western Poland. Eur J Wildl Res 59:581-586

Papakosta M, Kitikidou K, Bakaloudis D, Vlachos C (2014) Dietary variation of the stone marten (Martes foina): a meta-analysis approach. Wildl Biol Pract 10:85-101

Pedrini P, Prigioni C, Volcan G (1995) Use of trophic resources and forest habitats by the genus Martes in Adamello-Brenta Park (central Italian Alps). Hystrix 7:127-135

Pilot M, Gralak B, Goszczynski J, Posłuszny M (2007) A method of genetic identification of pine marten (Martes martes) and stone marten (Martes foina) and its application to faecal samples. J Zool 271: 140-147

Prigioni C, Balestrieri A, Remonti L, Cavada L (2008) Differential use of food and habitat by sympatric carnivores in the eastern Italian Alps. Ital J Zool 75:173-184

Revilla E, Palomares F (2002) Does local feeding specialization exist in Eurasian badgers? Can J Zool 80:83-93

Reynolds P (1979) Preliminary observations on the food of the fox in the Camargue, with special reference to rabbit predation. Mammalia 43: 295-307

Reynolds JC, Aebischer NJ (1991) Comparison and quantification of carnivore diet by faecal analysis: a critique, with recommendations, based on a study of the fox Vulpes vulpes. Mammal Rev 21:97-122

Rosenzweig ML (1966) Community structure in sympatric Carnivora. J Mammal 47:602-612

Ruiz-Olmo J, Jiménez J (2009) Diet diversity and breeding of top predators are determined by habitat stability and structure: a case study with the Eurasian otter (Lutra lutra L.). Eur J Wildl Res 55:133-144

Ruiz-Olmo J, Blanch F, Vidal F (2003) Relationships between the red fox and waterbirds in the Ebro Delta Natural Park, NE Spain. Waterbirds 26:217-225

Santos MJ, Pinto BM, Santos-Reis M (2007) Trophic niche partitioning between two native and two exotic carnivores in SW Portugal. Web Ecol 7:53-62

Schoener TW (1974) Resource partitioning in ecological communities. Science 185:27-39

Scott DM, Joyce CB, Burnside NG (2008) The influence of habitat and landscape on small mammals in Estonian coastal wetlands. Estonian J Ecol 57:279-295

Serafini P, Lovari S (1993) Food habits and trophic niche overlap of the red fox and the stone marten in a Mediterranean rural area. Acta Theriol 38:233-244

Soe E, Davison J, Süld K, Valdmann H, Laurimaa L, Saarma U (2017) Europe-wide biogeographical patterns in the diet of an ecologically and epidemiologically important mesopredator, the red fox Vulpes vulpes: a quantitative review. Mammal Rev 47:198-211

Sulkava R (1996) Diet of otters (Lutra lutra) in Central Finland. Acta Theriol 41:395-408

Tast J (1966) The root vole, Microtus oeconomus (Pallas), as an inhabitant of seasonally flooded land. Ann Zool Fenn 3:127-171 
Tátrai I, Kálmán M, Korponai J, Paulovits G, Pomogyi P (2000) The role of the Kis-Balaton water protection system in the control of water quality of Lake Balaton. Ecol Eng 16:73-78

Teerink BJ (1991) Hair of west-European mammals. Cambridge Univ. Press, Cambridge

Torre I, Arrizabalaga A, Flaquer C (2004) Three methods for assessing richness and composition of small mammal communities. J Mammal 85:524-530

Torre I, Arrizabalaga A, Freixas L, Ribas A, Flaquer C, Díaz M (2013) Using scats of a generalist carnivore as a tool to monitor small mammal communities in Mediterranean habitats. Basic Appl Ecol 14:155-164

Tousignant M-ÊE, Pellerin S, Brisson J (2010) The relative impact of human disturbances on the vegetation of a large wetland complex. Wetlands 30:333-344

Verboom J, Alkemade R, Klijn J, Metzger MJ, Reijnen R (2006) Combining biodiversity modelling with political and economic development scenarios for 25 EU countries. Ecol Econ 62:267-276
Webbon CC, Baker PJ, Harris S (2004) Faecal density counts for monitoring changes in red fox numbers in rural Britain. J Appl Ecol 41: 768-779

Weber JM (1990) Seasonal exploitation of amphibians by otters Lutra lutra in north-East Scotland. J Zool 220:641-651

Zar HR (2010) Biostatistical analysis. Prentice Hall Publishers, Upper Saddle River

Zhou YB, Newman C, Xu WT, Buesching CD, Zalewski A, Kaneko Y, Macdonald DW, Xie ZQ (2011) Biogeographical variation in the diet of Holarctic martens (genus Martes, Mammalia: Carnivora: Mustelidae): adaptive foraging in generalists. J Biogeogr 38:137147

Publisher's note Springer Nature remains neutral with regard to jurisdictional claims in published maps and institutional affiliations. 